\title{
NA VAS PO ZNANJE
}

prof. dr. Ana

Krajnc

\section{Izobraževanje kot turistična ponudba zavoda za ohranjanje dediščine "Muzej jezerski hram" ob Cerkniškem jezeru}

Čeprav vemo, da skoraj ni kraja, kjer se ne bi pojavljalo tudi izobraževanje, nas je presenetil primer $v$ Dolenjem Jezeru, vasici ob Cerkniškem jezeru. Lahko bi rekli, da v zadnjih letih Cerknica ubira velike razvojne korake. Dokončani sta prenova in posodobitev velike stavbe za knjižnico, tik ob njej bo v samem središču Cerknice nastal muzej. V knjižnici pripravljajo tudi različne oblike izobraževanja odraslih: center za samostojno učenje, študijske krožke, borzo znanja in univerzo za tretje življenjsko obdobje. V prihodnje bi radi imeli ljudsko univerzo in še kaj. Skoraj nezaslišano je, da je država ljudi cerkniške občine in sosednjih občin pustila tako na cedilu, da jim ni organizirala niti ene srednje šole za celoten okoliš, kaj šele kako višjo ali visoko šolo, ki bi jo $\mathrm{v}$ sodobnem času nujno potrebovali. Imajo samo osnovne šole, tako kot pred 150 leti.

Zakaj bi okolje potrebovalo bolj izobražene ljudi? Prehod iz industrijske ekonomije v informacijsko zahteva ogromno znanja in kulture, Tudi v Cerknici se je ekonomija v zadnjem desetletju bistveno spremenila. Včasih je bilo vse osredotočeno samo na tovarno Brest Cerknica, kraj skoraj ni bil zaznaven. Tovarna je bila uspešna in znana. Po poljih so se širile nove industrijske hale in novi obrati. $\mathrm{K}$ uspehu so veliko prispevali delavci in vsi zaposleni. V tovarni je ostala življenjska moč in pribranki mnogih ljudi, saj so delali za male plače. V devetdesetih letih so se stvari tudi v Cerknici obrnile. Tovarna Brest je izgubljala svoj prejšnji položaj in se kmalu znašla v zasebnih rokah. Ljudje kot da so že pozabili nanjo, saj življenje nastaja drugje. $\mathrm{O}$ Brestu se danes malo govori. Tovarna deluje le še v skrčenem obsegu, proizvajajo predvsem za izvoz. Kot druge tovarne se mora tudi ta boriti za čim višjo kakovost in konkurenčne cene. Število zaposlitev se je zelo skrčilo, ostala je le še peščica ljudi.

\section{PREŽIVET]E PO LASTNI ZAMISLI IN NENEHNO IZOBRAŽEVANJE}

V nekdanje industrijske dvorane Bresta so se naselile različne storitvene dejavnosti, servisi, mala družinska podjetja itd. Prej so bili ljudje množično zaposleni v eni tovarni, sedaj je preživetje $v$ večji meri odvisno od osebnih rešitev. V informacijski družbi ni več enega samega vzorca za preživetje, ljudje preživijo na različne načine. Vsak si po svoje pomaga, odvisno je od tega,
Prehod iz industrijske $v$ informacijsko družbo je zajel tudi podeželje. kaj zna in zmore. Tudi $v$ Cerknici ljudje poskušajo razne stvari, kakor se kdo znajde, prehod iz industrijske $\mathrm{v}$ informacijsko družbo pa je očiten. Kako se porajajo gospodarski in družbeni razvoj, razvoj ljudi in krajev? Ljudje se učijo tudi zato, da bi našli rešitve za svoje probleme. Pogledali smo si, kakšne rešitve so našli ljudje, ko so odkrivali nove načine preživetja. 
Cerknica in sosednje občine nimajo srednjih šol, imajo pa zelo uspešno razvojno službo. Notranjski ekološki center, ki ga vodi gospa Lili Mahne, je srce razvoja v okolju. Pred očmi imajo vsako vasico in skupaj z ljudmi odkrivajo, kakšen je njihov korak $v$ prihodnost. Vsi sodelujoči morajo imeti veliko poguma, medsebojnega zaupanja in tudi drznosti; biti morajo sanjači in hkrati realisti na trdnih nogah vsakdanjosti. Predvsem pa se morajo biti vsi, tako razvojne službe kot tudi vaščani, pripravljeni neprestano učiti. "Brez stalnega izobraževanja ni nič. Ne morete nič. Ne pridete nikamor," pravi Vekoslav Kebe iz Dolenjega Jezera, male vasice tik ob Cerkniškem jezeru. Svoje vtise in spoznanja o Cerkniškem jezeru in okolici je nabiral od najbolj ranega otroštva dalje. Ko se je odločil, da bo postavil na noge muzej in našel zase novo obliko preživetja, je želel svoje znanje izpopolniti in poglobiti. Obrnil se je tja, kjer ga imajo največ: na znanstvenike Univerze v Ljubljani, Prirodoslovni muzej, Inštitut za proučevanje krasa itd. "O jezeru sem marsikaj vedel, vendar tu ni konca. Spoznanja se širijo. Nikoli ne bom mogel vsega izčrpati, čeprav bom šel po poti stalnega izobraževanja. Ni konca pojavov, ki jih lahko še spoznaš. Učenje je res neskončen proces," meni Kebe. Njegov projekt je eden od razvojnih projektov na vasi in spada med najuspešnejše.

\section{MUZEJ JEZERSKI HRAM KOT IZOBRAŽEVALNO SREDIŠČE}

Če se iz Cerknice podate po ravni poti proti jezeru, se na koncu poti, tik ob jezeru, znajdete v Dolenjem Jezeru. Strnjena povezava vasice je videti kot gnezdo. Travniki, njive in dno jezera sežejo do hišnih pragov. Vas je ostala enaka. Obiskovalec skoraj ne more slutiti, kakšno presenečenje ga čaka v njej. Sploh smo bili navajeni, da imamo do vasi brezbrižen odnos in smo vse stavili samo na glavno mesto. Notranjski ekološki center se tu lahko pohvali še s posebnimi uspehi.

Vekoslav Kebe pravi o sebi: "Jaz sem kmet. Izučil sem se za strojnika. Ko sem izgubil službo, nisem vedel, kaj bi. To so bili zame hudi časi. V pogovorih s predstavnico razvojne službe sem odkrival, kaj bi lahko počel. Stvari so se začele odvijati. Svoje znanje sem uspel na razne načine ponuditi drugim in si hitro pridobival nova znanja. Danes imam zavod za ohranjanje dediščine, katerega osnovna dejavnost je izobraževanje. Človek se mora vse življenje učiti. Drugače

"Pri razvoju stvari nikoli ne gredo kar gladko. Staro se vedno upira novemu, pa naj bo še tako v prid ljudem in njihovemu življenju. Čeprav star način preživetja ni več možen, se ga ljudje oklepajo, ker ga poznajo. Novih stvari se neradi lotevajo, zato je pomembno, da jim pomagamo premagati strah. Naš predlog ali zamisel ljudem na vasi najprej omenimo. Pustimo jim čas, da o tem sami premislijo. Nato se vračamo in z njimi pogovarjamo. Včasih pridobimo enega iz družine, pa mu drugi doma še vedno nasprotujejo in potrebujejo več časa, da stvari dozorijo v odločitve. Pogovori postopoma preidejo v prepričevanja. Ko ljudje vidijo, da njihove predloge upoštevamo, se jim vedno bolj zdi, da je to 'njihova stvar'. Věasih pogovori trajajo tri ali štiri mesece. Če so uspešni, preidemo k odločitvam in dejanjem, kot so najemanje kreditov, urejanje prostorov, izbiranje imena, razvijanje osnovne dejavnosti, ustvarjanje socialnih mrež povpraševanja in povezovanje z zaledjem, Seveda se na poti od prve zamisli do cilja marsikaj zgodi in opisovali bi lahko še veliko podrobnosti. V vsaki vasi in pri vsaki družini ali projektu so drugačne."

Lili Mahne, Notranji ekološki center 
ne gre. Tudi jaz se kar naprej učim. Ko smo z vodjo razvojne službe iskali nekaj, od česar bi lahko živela moja družina, sem odkril, da je edino, kar res poznam, jezero. Jezero in okolico sem spoznaval od rojstva. Z njim sem živel. Ta del narave poznam $v$ vseh odtenkih in podrobnostih. Drugega kot to ne znam, vendar si nisem predstavljal, kako bi si s tem znanjem lahko pomagal."

Pomembno je vplivala svetovalka iz razvojne službe. Vedela je, koliko lahko tako znanje pomeni za razvoj kraja in kako dragoceno je tudi za širšo slovensko javnost, obenem pa lahko zagotavlja preživetje nekaj ljudem. Zato se je začelo trdo delo postavljanja obsežnega projekta: Muzeja jezerski hram. "Sodeloval sem z raznimi ustanovami in posameznimi strokovnjaki. Načrtoval, pripravljal maketo, elektronsko opremo za prikaz celoletne dinamike Cerkniškega jezera, povezal sem se $\mathrm{z}$ ljudmi za prevode besedil, urejal prostore in postavljal muzejsko zbirko. Začel sem se ukvarjati tudi s fotografijo. Za lažje prenašanje znanja sem napisal knjižico. Ravnokar je izšla." Trajalo je več let, da je dejavnost dobila današnjo obliko in vsebino. Ministrstvo za gospodarske dejavnosti je ravnokar izdalo odločbo, s katero je Vekoslava Kebeta imenovalo izumitelja. Njegovi izumi so izobraževalni pripomočki za predstavljanje Cerkniškega jezera.

Ne da bi videli, si težko vse to predstavljamo, ker je toliko novega in originalnega za naše okolje, kar še nismo videli in si zato težko predstavljamo. Kebetov zavod za ohranjanje dediščine je posvečen Cerkniškemu jezeru in življenju ob njem.

\section{VZGOJNI CILII IN IZOBRAŽEVALNI PRIPOMOČKI}

Pred hišo je pod steklom mala maketa Cerkniškega jezera, ki opozarja na bistvo tistega, kar obisk in ogled zavoda nudi. $\mathrm{Na}$

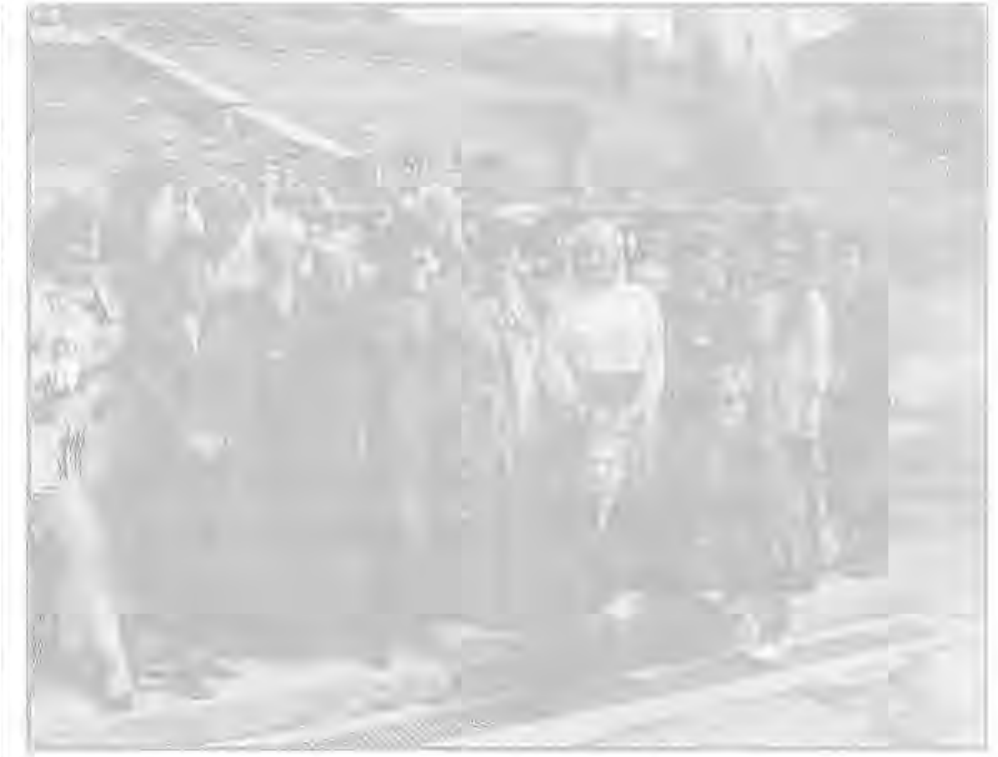

drogu ob njej visi rumena zastava zavoda in ob vhodu na dvorišče je kiosk $\mathrm{z}$ razglednicami. Skozi vrata pridete $\mathrm{v}$ neke vrste sprejemnico. Tu dobite prve informacije, poravnate ystopnino, popijete sok ali čaj in se še malo pogovorite, preden se začne izobraževalni program. Postreže vam Kebetova žena in pove marsikaj zanimivega, saj skrbno bedi nad vsem. Mož ima polne roke dela $\mathrm{z}$ obiskovalci. Ti se začnejo učiti, ne da bi se tega posebej zavedali. Izobraževanje ubira naravne poti, zato pri učečih ne poraja odpora. Vse je le zelo zanimiv in sproščujoč dogodek. Ko smo prišli, je bilo zunaj v vrsti 30 koles. Na zavodu so se ravnokar učili osnovnošolci in učitelji iz Prekmurja, ki preživljajo dneve v Centru obšolskih dejavnosti $\mathrm{v}$ ne tako oddaljenem Rakovem Škocjanu. Sem prihajajo tudi razni drugi radovedneži, od znanstvenikov, ki kaj raziskujejo, do običajnih turistov.

Kebe si je belil glavo, kako bi vse to, kar ve, in še kaj povedal drugim, kako bi ljudem jezero predstavil, če pridejo takrat, ko jezero izgine in ga ne more pokazati. Po dolgih premišljevanjih, posvetih in pogovorih so se rojevale originalne zamisli. Nastajalo je 
izobraževalno žarišče, ki ga drugje ne moremo videti. Vanj je po Kebetovih zamislih ujeta celoletna dinamika delovanja Cerkniškega jezera.

Cilj izobraževalnega programa je spoznavanje presihajočega Cerkniškega jezera, ki je posebnost vse Slovenije in ne samo

Izobraževalni program o Cerkniskem jezeru je plod vašcanov. tamkajšnjega okolja. Ob njem naj bi spoznali tudi ljudi, njihove navade in način življenja nekoč in danes.

Izobraževanje se loči od drugih dejavnosti, saj je naravnano $\mathrm{k}$ spoznavnim ciljem

in primerno strukturirano ter didaktično izvedeno. Izobraževalni program o Cerkniškem jezeru je pregledno razdeljen na vzgojne podcilje. Enako si sledijo tudi izobraževalne teme, na katere je program razdeljen. Obiskovalci lahko spoznajo:

- ljudsko izročilo in legende o Cerkniškem jezeru,

- zgodovino Cerkniškega jezera, tako kot ga obravnavajo prejšnji pisci od Valvazorja dalje,

- raziskovalce in opisovalce Cerkniškega jezera,

- Cerkniško jezero kot kraški pojav,

- Cerkniško polje y središču Notranjske (geografski vidik),

- življenje ob jezeru in z jezerom (etnološki vidik),

- stari način ribolova in pripomočke ter stare pravice ribolova posestnikov,

- rastlinstvo Cerkniškega jezera,

- ptiče in druge živali Cerkniškega jezera in okolice,

- vodnogospodarske posege v Cerkniško jezero.

Za izobraževalni program so vsebine črpali iz del dr. Petra Habiča, dr. Franceta Habeta, Andreja Kranjca in Jožefa Žirovnika ter drugih knjig. Pri sestavljanju programa so sodelovali še Dare Šare s Prirodoslovnega muzeja Slovenije in Peter Škoberne. Pri oblikovanju izobraževalnega programa je moral avtor brskati tudi po arhivih in zbirati podatke neposredno med ljudmi, ker se je marsikaj ohranilo le $v$ ljudskem izročilu. Nastajanje programa je bilo zelo razvejano in strokovno podprto delo.

Izobraževanje poteka $v$ nekaj različicah. Za otroke je program krajši, Zanimajo jih samo nekatere stvari, medtem ko se odrasli obiskovalci poglobijo $\mathrm{v}$ razne pojave in je zanje izobraževanje izčrpnejše. Z nekajletno prakso je mentor razvil občutek, kako se pri podajanju prilagoditi publiki in predstaviti ter poudariti to, kar najbolj želijo. Zato na različne načine kombinira izobraževalna sredstva, izobraževanje pa tako postane veliko doživetje.

Ljudje si pri enem obisku, med predstavitvijo in demonstracijo dinamike jezera na maketi ter $\mathrm{z}$ ogledom muzejske zbirke, ne morejo vsega zapomniti. Zato je pomembno, da lahko vzamejo s seboj knjižico in pozneje o vsem $v$ skrajšsani obliki še sami večkrat preberejo.

Predstavitev traja približno eno uro. Maló dvorano $v$ pritličju pokriva maketa Cerkniškega jezera $\mathrm{z}$ vsemi okoliškimi vasmi in Cerknico v velikosti $1: 25.000$. Maketa je multimedijsko in računalniško opremljena z daljinskim upravljalnikom. Cerkniško jezero se nam začne predstavljati $v$ pomladnem času, $\mathrm{z}$ deževjem, petjem ptic in vodnimi izviri. To, kar slišite, se na maketi tudi prikaže. Voda zaliva jezero na isti način kot $v$ naravi. Poletje, jesen in zima pokažejo še druge značilnosti jezera. Vse spremlja razlaga o jezeru in z njim povezanih pojavih. Besedilo lahko poslušate v knjižni slovenščini, domači govorici, nemščini ali angleščini. Celotno izobraževanje traja približno eno uro. 


\section{IZOBRAŽEVALNA POT}

Maketa je glavni izobraževalni pripomoček v Kebetovem zavodu, ni pa edini. Izobraževalna pot se nadaljuje na dvorišče, kjer je pod steklom s posebnimi napisi opremljen iz debla stesan cerkniški čoln ter vse orodje, $s$ katerim so čoln ljudje nekoč izdelovali. Ljudje ob jezeru so večinoma živeli od ribolova. Zato je v prvem nadstropju poleg dvorane za predavanja (opremljene $\mathrm{z}$ najsodobnejšo izobraževalno projekcijsko tehnologijo) še muzej ribiške opreme. Samo dogajanje med ribolovom prikazujejo plakati, delo domačega cerkniškega slikarja in ilustratorja Slavka Mikše, ki predstavljajo tudi del izobraževalnih pripomočkov.

Obiskovalci slišijo veliko novega, omenjenih je veliko podrobnosti in polni so vtisov. Mentorja Kebeta je skrbelo, ali si bodo ljudje vse to lahko zapomnili, saj imajo na razpolago sorazmerno kratek čas. Zato se je odločil, da napiše knjigo, kjer bo vse to, kar v izobraževalnem programu ponudi in pove, tudi zapisal. Ravnokar je izšla njegova prva knjiga, ki je privlačne zunanjosti, slikovno in z ilustracijami bogato opremljena, prav tako pa tudi z dokumentacijskim gradivom, ki ga je zbral avtor. Zadnja štiri leta se zelo intenzivno ukvarja tudi s fotografijo.

Vtisi in spoznavanje Cerkniškega jezera se še poglobi, če se obiskovalci odločijo za vožnjo z lojtrnikom okoli Cerkniškega jezera, ki jo ponuja ena od domačij $\mathrm{v}$ vasi. Lepo vzdrževana makadamska cesta obkroža jezero in konjska vprega ponuja primerno hitrost, da si neposredno ogledujemo jezero, gozdove, pašnike in okoliške vasice. Priložnost imamo, da še sami povprašamo ljudi o tem in onem. Če smo dovolj radovedni, si naberemo še veliko znanja. Od naše osebne motivacije za izobraževanje je odvisno vsako neformalno izobraževanje, ko znanje nabiramo iz okolja.

\section{NOVA PONUDBA IZOBRAŽEVALNEGA TURIZMA KOT PRISPEVEK K RAZVOJU KRAJA IN DRŽAVE}

Za Cerkniško jezero in njegovo posebnost smo vsi vedeli. Toda ljudje tja nismo množično ali pogosto zahajali, tako kot zahajamo na primer v Postojnsko jamo, ker smo o jezeru premalo vedeli in tam ni bilo na ogled nič organiziranega. Tudi svojih gostov nismo tja vozili. Kaj pa naj jim rečemo? Še sami smo premalo vedeli o tem svetovno znanem pojavu. Danes je ta problem rešen. $\mathrm{V}$ enem dnevu sprejme Muzej jezerski hram poleg manjših skupinic obiskovalcev in posameznikov tudi tri in več avtobusov ljudi. Mentor se spominja najbolj utrudljivega dne, ko je bilo obiskovalcev

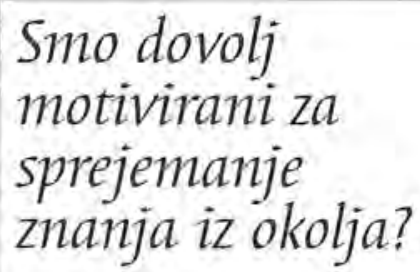
za polnih trinajst avtobusov. Na koncu dne je tudi mentor Kebe potreboval miren sprehod ob jezeru, da je pogasil svojo izčrpanost.

Pri množičnejših obiskih in osnovni predstavitvi izobraževalnega programa je precej $\mathrm{v}$ pomoč že posneta razlaga $\mathrm{v}$ zvezi $\mathrm{z}$ maketo. Posneta je $v$ domačem narečju, knjižni slovenščini, angleščini in nemščini. $\mathrm{Na}$ organiziran način lahko spoznamo $\mathrm{v}$ Muzeju jezerski hram vse, kar nas o jezeru in okolici zanima, pa še kaj več.

Obiskovalci radi kaj pojedo, posedijo in se pogovorijo, vožnja z lojtrnikom postaja vedno bolj priljubljena. Vse to ponujajo druge domačije v vasi. Dejavnosti so nastajale po naravni poti glede na želje in povpraševanje turistov.

Dolenje Jezero je odmaknjena mala vasica. $\mathrm{Na}$ videz tiha, kot je večina vasi. V njej pa se vedno več dogaja. Število obiskovalcev Zavoda narašča. Lansko leto se je celo zgodilo, da je prišlo tja na en dan 13 avtobusov. Zamislite si napor učitelja Kebeta, 
Razvojni projekti so primeri, ki dokazujejo, kako stvari potekajo interdisciplinarno in da se ni mogoče zanašati samo na eno znanost, ampak je timsko sodelovanje ljudi garancija uspeha. Pokažejo nam nove podobe vseživljenjskega ali permanentnega izobraževanja. Pričajo nam, kako globoko zaorjejo izobraževalne poti tudi izven pouka, koliko pomembnega učenja nastaja na spontan način, med ljudmi.

ki je moral sam vsem tem ljudem obrazložiti in pokazati vse o jezeru.

Obiskovalci pa imajo še druge potrebe in želje. Tako se širijo v vasi še druge dejavnosti. $\mathrm{Na}$ dveh domačijah pripravljajo hrano in jim je to dodatna dejavnost na kmetiji, eden od gospodarjev je ponudil vožnjo z lojtrnikom okoli jezera. Vse naznanjajo lične table $\mathrm{z}$ napisi. Porajajo se nove oblike preživetja, pri vsaki hiši nekaj drugega. Kraj se vedno bolj prebuja. Vaščani se učjo eden od drugega. V vasi so začele prevladovati nove vrednote. Nič več ne čakajo na delo $v$ tovarni ali na službo. Postopoma jemljejo življenje v svoje roke in odločajo sami. Vas je zaživela $v$ novi ekonomiji. Primer nastale turistično izobraževalne ponudbe je pomemben prispevek $\mathrm{k}$ razvoju vse Slovenije. Vseh gostov ne bo treba več voditi samo na Bled, ker nastajajo nova turistično pomembna žarišča.

Vaščani se zavedajo, da sami brez razvojne občinske službe ne bi mogli vsega tega organizirati. Ljudje iz razvojne službe so pri njih dobrodošli, saj imajo vedno nove dobre predloge, ideje pa jim tudi pomagajo uresničevati: pomagajo pri pridobivanju raznih dovoljenj, ko je treba dejavnost uradno registrirati, poiskati možnosti za kreditiranje in dejavnost primerno socialno umestiti. Podpirajo jih na poti do cilja.

Kebe si je večino svojega znanja pridobil po neformalni poti. Kako in kdo mu bo to tudi formalno priznal, je bilo veliko vprašanje in šele odločba ministrstva o izumiteljstvu mu je odprla pot do izobraževalne dejavnosti. Kako bodo to reševali $v$ prihodnje drugi ljudje $v$ podobnih situacijah? Znanje, pridobljeno tudi po neformalni poti, bo vedno bolj dragoceno in morda celo odločilno za preživetje določenih ljudi.

Vasi se naglo spreminjajo in urbanizirajo, ne da bi se tega posebej zavedali. Na površje prihajajo ljudje, ki se v prejšnjih časih niso imeli priložnosti šolati. Znanje so si nabirali predvsem izkušenjsko, po neformalnih poteh. Sedanji, vedno bolj selektivni, $v$ devetdesetih letih reformirani šolski sistem jim ni v prid. Še naprej bodo zaostajali za drugimi v uradno priznani izobrazbi in jih bo to zelo oviralo pri iskanju poti za preživetje, saj se od kmetovanja ne da več živeti, $v$ tovarnah pa ni več množičnega zaposlovanja. Splošna družbena potreba postaja, da ljudem, ki kaj znajo, tudi formalno priznamo njihovo znanje. V prihodnje bodo ljudje živeli od svojega znanja, idej, zamisli in ustvarjanja. V informacijski družbi bi zaman ponujali delo mišic, kot smo ga prej $\mathrm{v}$ industrijjskem obdobju. 